\title{
Opportunistic macroalgae metrics for transitional waters. Testing tools to assess ecological quality status in Portugal
}

\author{
J. Patrício *, J.M. Neto, H. Teixeira, J.C. Marques \\ IMAR - Institute of Marine Research, clo Department of Zoology, Faculty of Sciences and Technology, \\ University of Coimbra, 3004-517 Coimbra, Portugal
}

\begin{abstract}
Macroalgae communities constitute one of the ecological quality elements for the evaluation of the ecological quality status (EQS) of coastal and transitional waters, required to implement the WFD. While these algae are natural components of estuarine systems and play important roles in several estuarine processes, macroalgal blooms are of ecological concern because they can reduce the habitat quality. Several works are being carried out to set standard methods for monitoring macroalgae blooms, in order to develop tools to derive EQS based upon this biological quality element. The aim of this paper is to apply the methodology described by Scanlan et al. [Scanlan, C.M., Foden, J., Wells, E., Best, M.A., 2007. The monitoring of opportunistic macroalgal blooms for the water framework directive. Marine Pollution Bulletin 55, 162-171] to a series of data assembled in the south arm of the Mondego estuary (Atlantic coast of Portugal) considering two different ecological situations. Additionally, an alternative assessment method intended to be used when no biomass data are available was also tested. In general, both options captured the inter-annual variations in accordance with the system evolution. Option 2, less expensive and time-consuming, allowed an EQS evaluation with accurate results when biomass data were not available. The results suggest that sampling should be carried out from April to June.
\end{abstract}

(c) 2007 Elsevier Ltd. All rights reserved.

Keywords: WFD; Transitional waters; Opportunistic macroalgal blooms; Metrics; Eutrophication; Portugal

\section{Introduction}

The water framework directive (WFD) aims at achieving "good water status" for all European waters by 2015. The WFD requires member states to assess the ecological quality status (EQS) of water bodies. The EQS will be based upon the status of the biological, hydromorphological and physicochemical quality elements, with the biological elements being particularly important. In coastal and transitional waters, the biological elements to be considered are phytoplankton, macroalgae and angiosperms, benthos and fishes (the latter only in transitional waters) (EEC, 2000).

Plant and animal communities are often used in ecological assessment as bioindicators of ecological status (Dauer,

\footnotetext{
* Corresponding author. Tel.: +351 239 836386; fax: +351 239823603. E-mail address: jpatricio@ci.uc.pt (J. Patrício).
}

1993; Bricker et al., 1999; Gibson et al., 2000; EEC, 2000), because long-term anthropogenic stress is often reflected at community level (Odum, 1985; Crowe et al., 2000). However, the evaluation of the ecological status is often a difficult task because of spatial and temporal community variability. Consequently, the central issue in the management of "high" valued transitional and coastal ecosystems (Constanza et al., 1997) is the identification of key signals that indicate the degree of human impact or ecological status (Crooks and Turner, 1999).

Macroalgae communities constitute one of the ecological quality elements for the evaluation of the EQS of coastal and transitional waters, required to implement the WFD, the legislation targeted at sustainable management of the European aquatic environment (Panayotidis et al., 2004). Unfortunately, large blooms of opportunistic green macroalgae occur in estuaries throughout the world (e.g. Sfriso et al., 1992; Schramm and Nienhuis, 1996; Raffaelli 
et al., 1999), often in response to increased nutrient loads from developed watersheds (Valiela et al., 1992; Nixon, 1995; Paerl, 1999). While these algae are natural components of estuarine systems and play integral roles in several estuarine processes macroalgal blooms are of ecological concern because they can reduce the habitat quality of transitional water systems. Ultimately, they can deplete the water column and sediments of oxygen (Sfriso et al., 1992) leading to changes in species composition, shifts in community structure (Thiel and Watling, 1998), and loss of ecosystem function. Although profusely identified and studied, it is clear that the occurrence, persistence and impacts of macroalgal blooms are governed by a number of physical, chemical and biological factors, which may interact in a complex way, and are often difficult to fully characterise and understand (Scanlan et al., 2007).

Due to this, several works are being carried out to set up standard methods for monitoring macroalgae blooms, in order to develop tools to derive EQS based upon this biological quality element. Recently, Scanlan et al. (2007) published a paper describing the underlying philosophy of the approach taken by the United Kingdom and Republic of Ireland to the development of a tool for monitoring mats of various bloom-forming algae on sedimentary shores, and made an attempt for WFD class boundaries, considering eutrophication has the main pressure. This metric was designed to: (1) cover the pre-requisites of European WFD, which will be the operational tool setting the objectives for water protection well in Europe (EEC, 2000), and (2) it will offer to water managers a tool for comparing, ranking and setting management priorities at different spatial levels, e.g. regional or national.

In parallel to this process, the issue of inter-comparability of methods or inter-calibration has emerged as an obligation to the Directive but also as an occasion to test and validate classification tools (EC, 2003). The Portuguese National Water Institute (INAG) has decided to actively participate in this exercise.

In this context, the aim of this paper is to apply the methodology described by Scanlan et al. (2007) to a series of data assembled in the south arm of the Mondego estuary (Atlantic coast of Portugal) considering two different situations: a period where clear eutrophication symptoms were observed (1993-1997) and a period following the implementation of experimental eutrophication mitigation measures (1998-2000). We consider this transitional water system (TW) as highly suitable for testing and discussing such type of tools due to the availability of long-term data sets (approximately two decades) and its well known temporal response to anthropogenic influences (namely nutrient enrichment) (Marques et al., 1997, 2003; Martins et al., 2001; Cardoso et al. 2004, 2007; Verdelhos et al., 2005; Neto et al., in press). It is reasonable to assume that the tools tested and calibrated might be also applicable to sheltered coastal waters systems $(\mathrm{CW})$ where macroalgal growth and accumulation may frequently occur. Additionally, an alternative assessment method (Option 2) which can be used, when no biomass data are available, was also tested.

\section{Material and methods}

\subsection{Opportunistic macroalgae methodology}

Scanlan et al. (2007) describe the underlying methodology of the approach taken to the development of a tool for monitoring mats of various bloom-forming algae on intertidal sedimentary shores, a phenomenon primarily of transitional waters and sheltered coastal areas, and of tentative values for WFD class boundaries. The main pressure considered was eutrophication.

\subsubsection{Sampling procedure}

The authors do not recommend any particular survey method to monitor macroalgal blooms, instead, they state that the pros and cons of survey methods, as well as costs, should be considered carefully. They enumerate a list of possible methodologies, from conventional techniques to remote sensing methods.

Regarding the sampling period Scanlan et al. (2007) claim that, depending on local patterns, it may be necessary to monitor in spring and summer. In the United Kingdom and Republic of Ireland, the peak biomass is most often found in late summer, so the abovementioned authors recommended that monitoring should take place during this period. Nevertheless, although they consider that, ideally, mats might be monitored throughout the growing season, they also state that this requirement would be highly resource intensive and could under-estimate impacts at peak times.

\subsubsection{Basic parameters}

A selection of tools was chosen based on those parameters that would describe or indicate the response of macroalgae to disturbance. It is not expected that any single tool would be used in isolation to understand ecological patterns or to derive a classification.

Four basic parameters have been proposed:

- Total available intertidal area for opportunistic macroalgae growth (ha).

- Areal coverage (ha).

- Percentage $(\%)$ cover.

- Biomass $\left(\mathrm{g} \mathrm{WW} \mathrm{m}^{-2}\right.$ ).

\subsubsection{Total available intertidal area for opportunistic} macroalgae growth (ha). In order to assess the ecological quality status of a given system it is necessary to define the intertidal area that may be suitable for macroalgal growth. Based on various published literature, Scanlan et al. (2007) considered suitable areas mud, muddy sand, sandy mud, sand, stony mud and mussel beds. Total available intertidal area is, thus, the total area available for 
growth when any known areas are excluded (Scanlan et al., 2007).

2.1.2.2. Areal coverage. This parameter is the total number of hectares of intertidal area effectively covered by macroalgae.

2.1.2.3. Percentage (\%) cover. According to Wither (2003), the system percentage cover would be assessed as follows:

If survey data show the following:

Total intertidal area available for opportunistic macroalgae growth $=75$ ha

50 ha with $0 \%$ cover;

10 ha with $1-25 \%$ cover;

10 ha with $26-50 \%$ cover;

5 ha with $100 \%$ cover.

The actual amount of substrate covered is

$$
\begin{aligned}
& ((((1+25) / 2 \times 10 / 100)+((26+50) / 2 \times 10 / 100) \\
& \quad+(100 \times 5 / 100)) / 75) \times 100=13.5 \% .
\end{aligned}
$$

2.1.2.4. Biomass. Macroalgae biomass values are expressed as wet rather than dry weight per square metre. For the sake of the classification, figures should be mean figures for the whole available intertidal area (Scanlan et al., 2007).

\subsubsection{Opportunistic macroalgae assessment} method-Option 1

Option 1 is the approach proposed by Scanlan et al. (2007). It combines in a first step the percentage cover with biomass in order to obtain a classification (see Table 1). For further details regarding boundary conditions please address the mentioned paper. Secondly, to account for overall water body size, the authors proposed that areal coverage (in hectares) should lower the class of a water body, as derived from Table 2, by one or more classes depending on the total area of algal mats (Scanlan et al., 2007).

\subsubsection{Opportunistic macroalgae assessment method-Option 2}

An alternative less-costly approach - Option 2 - is to combine only percentage cover with areal coverage (in hectares). Table 3 provides an initial classification status, but does not account for the overall size of the patch within the water body. Table 2, on the other hand, allows taking into account situations where there is a large algal bloom but $\%$ cover is relatively small due to the large size of the water body. Consequently, those areas where there is an extensive bloom of algae cannot achieve high status.

\subsection{Case study - opportunistic macroalgae in transitional waters}

\subsubsection{Study site: Mondego estuary}

The Mondego estuary is located on the western coast of Portugal (Fig. 1). Accordingly to the Portuguese typology for transitional and coastal waters the Mondego estuary belongs to the type A2, representative of a mesotidal well-mixed estuary with irregular river discharge (Bettencourt et al., 2004). Concerning the European classification it belongs to the North East Atlantic type 11 (TW -

Table 1

\begin{tabular}{|c|c|c|c|c|c|c|c|c|}
\hline \multirow{5}{*}{ 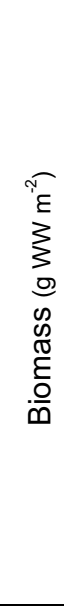 } & $>3000$ & \multicolumn{2}{|c|}{ M } & \multicolumn{2}{|c|}{$\mathbf{P}$} & \multicolumn{3}{|c|}{ B } \\
\hline & $1000-3000$ & \multicolumn{2}{|c|}{$\begin{array}{c}\mathbf{G} / \mathbf{M} \\
\text { (entrained algae - monitor) }\end{array}$} & M & $\begin{array}{c}\text { M / P } \\
\text { (entrained } \\
\text { algae- } \\
\text { monitor) }\end{array}$ & $\mathbf{P}$ & \multicolumn{2}{|c|}{ B } \\
\hline & $500-1000$ & \multicolumn{2}{|c|}{ G } & \multicolumn{2}{|c|}{$\begin{array}{c}\mathbf{G} / \mathbf{M} \\
\text { (entrained algae - monitor) }\end{array}$} & M & $\mathbf{P}$ & $\mathbf{P}$ \\
\hline & $100-500$ & H & $\begin{array}{c}\text { H / G } \\
\text { (entrained } \\
\text { algae - } \\
\text { monitor) }\end{array}$ & \multirow{2}{*}{\multicolumn{2}{|c|}{ G }} & \multirow{2}{*}{$\begin{array}{c}\text { G / / M } \\
\text { (entrained algae - } \\
\text { monitor) }\end{array}$} & M & $\begin{array}{c}\mathbf{M} / \mathbf{P} \\
\text { (entrained algae } \\
\text {-monitor) }\end{array}$ \\
\hline & \multirow[t]{3}{*}{$<100$} & \multicolumn{2}{|c|}{ H } & & & & $\begin{array}{c}\text { G / M } \\
\text { (entrained } \\
\text { algae - } \\
\text { monitor) } \\
\end{array}$ & $\mathbf{M}$ \\
\hline & & \multicolumn{2}{|c|}{$</=5$} & \multicolumn{2}{|c|}{$>5-15$} & $>15-25$ & $>25-75$ & $>75-100$ \\
\hline & & \multicolumn{7}{|c|}{$\%$ Cover } \\
\hline
\end{tabular}

Decision table for classification according to biomass and percentage cover (adapted from Scanlan et al., 2007)

Quality status: $\mathrm{H}$ - High, G - Good, M - Moderate, P - Poor and B - Bad. 
Table 2

Effect of total patch size on water body classification class (from Scanlan et al., 2007)

\begin{tabular}{ll}
\hline Areal coverage (ha) & Effect on classification class \\
\hline$<100$ & No change \\
$100-499$ & No change \\
$500-999$ & Downgrade by 1 class \\
$1000-2499$ & Downgrade by 2 classes \\
$>2500$ & Downgrade by 3 classes \\
\hline
\end{tabular}

NEA11), Oligo-Euhaline (0-35), Mesotidal (1-5 m), Shallow system $(<30 \mathrm{~m})$, Medium, Sheltered or moderately Exposed, Partially or Permanently Stratified, with a residence time of days-weeks.

This estuary consists of two arms, northern and southern, with very different hydrological characteristics. The northern arm is deeper (5-10 $\mathrm{m}$ during high tide) and constitutes the main navigation channel being subject to frequent dredging activities. The southern arm is shallower (2-4 m deep during high tide) and until 1997, was almost silted up in the innermost areas, which caused freshwater

Table 3

Decision table for classification according to percentage cover (from Scanlan et al., 2007)

\begin{tabular}{|c|c|c|c|c|c|}
\hline & \multicolumn{5}{|c|}{ Classification } \\
\hline & High $(\%)$ & Good & Moderate & Poor & $\mathrm{Bad}$ \\
\hline$\%$ Cover & $<5$ & $5-15$ & $15-25$ & $25-75$ & $>75$ \\
\hline
\end{tabular}

discharges mainly through the north arm. Water circulation was, until then, dependent on tidal activity and on the Pranto River freshwater input. This small tributary is artificially controlled by a sluice, located at $3 \mathrm{~km}$ from the confluence with the south arm, and regulated according to the irrigation needs in rice fields, located upstream (Flindt et al., 1997; Marques et al., 1993; Martins et al., 2001; Lillebø et al., 2005; Neto et al., in press).

This estuary has a significant regional importance, due to its high natural productivity and access facilities (Figueira da Foz harbour). Consequently, it has been exposed to considerable living resources exploitation and simultaneously it has been used as a receptacle of domestic, industrial and agricultural pollution. Due to large human intervention, its environmental quality has been progressively reduced. The interruption of the upstream communication between the north and south arms between 1992 until 1997, caused a rapid deterioration of ecological conditions in the south arm. In fact, the combined effect of increased water residence time and nutrients concentration became major driving forces causing the emergence of clear eutrophication symptoms, and the occurrence of large seasonal macroalgal blooms (mostly Ulva spp.) in the early 1990s. As a pattern, although we could observe some inter-annual variations as a function of hydrological conditions (e.g. Martins et al., 2001), Ulva spp. biomass tended to increase from early winter (February/March) up to July, when an algal crash usually occurred. A second but much

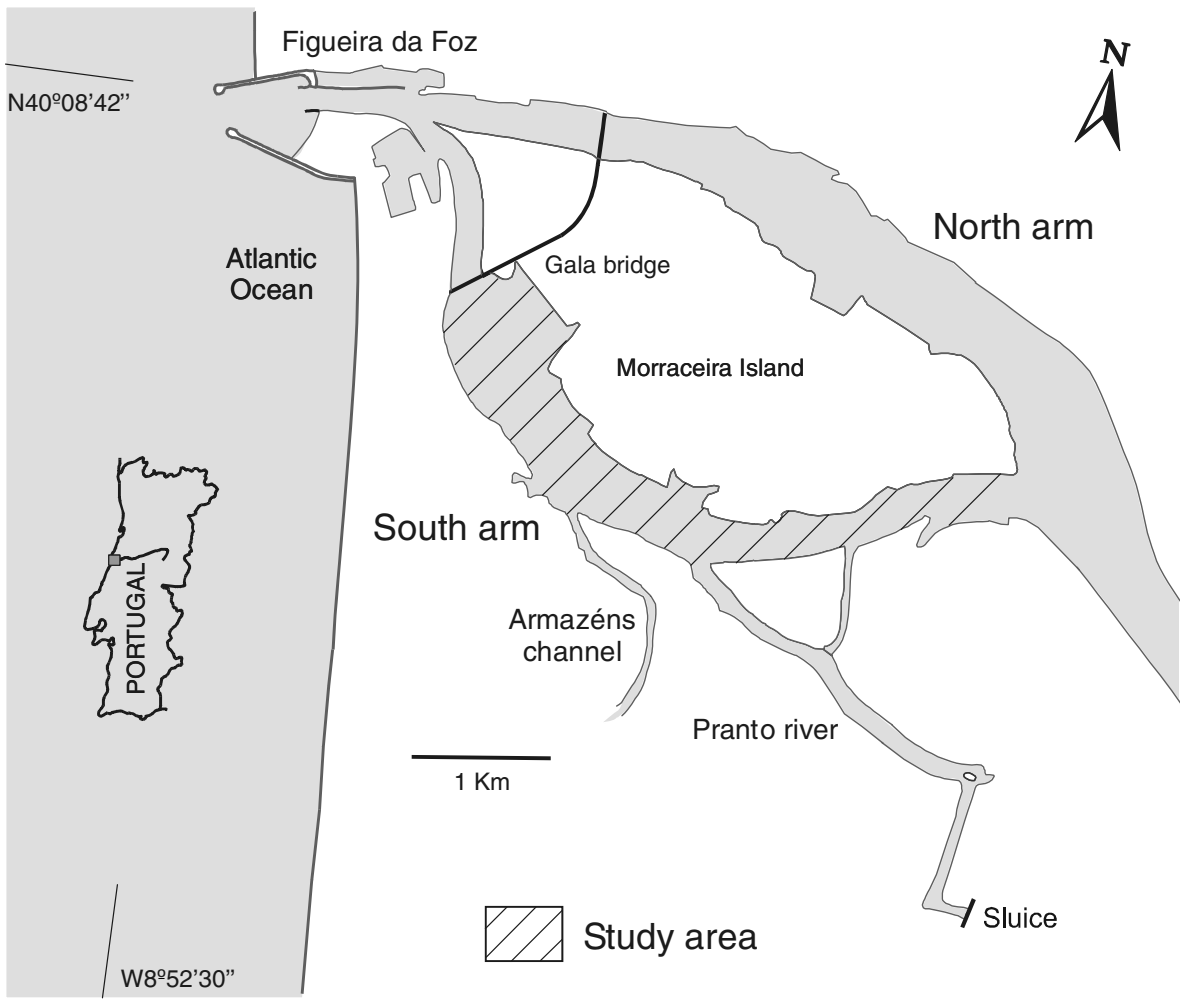

Fig. 1. Mondego estuary map, showing the study area in the south arm. 
A. Percentage Cover

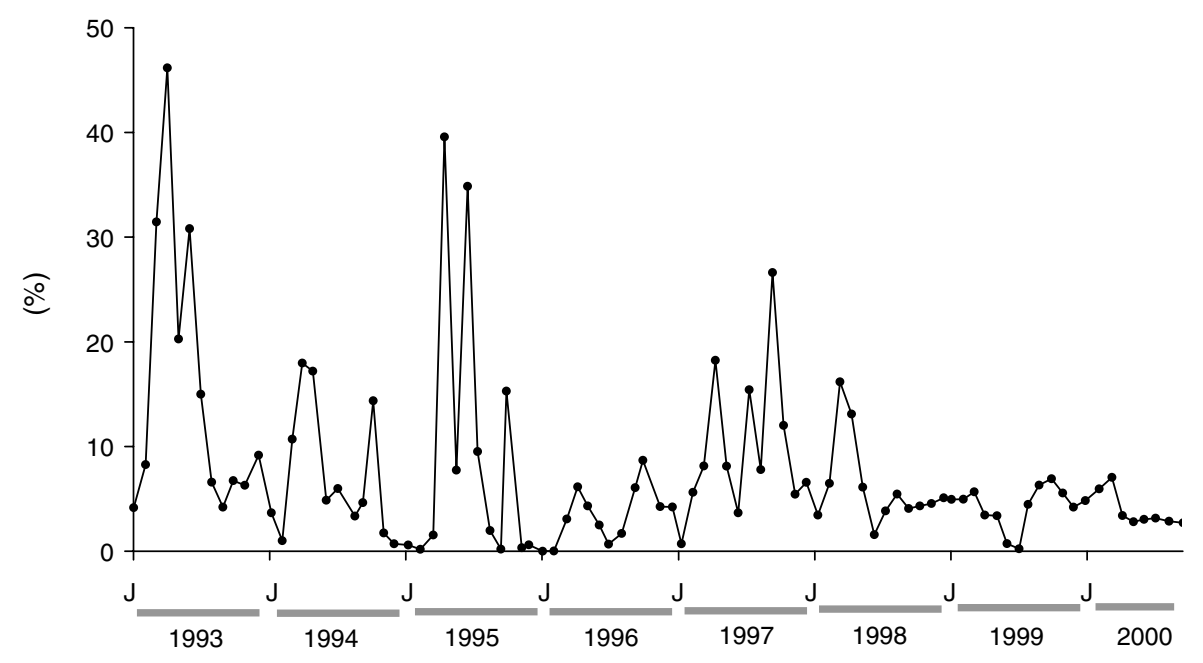

B. Mean Biomass

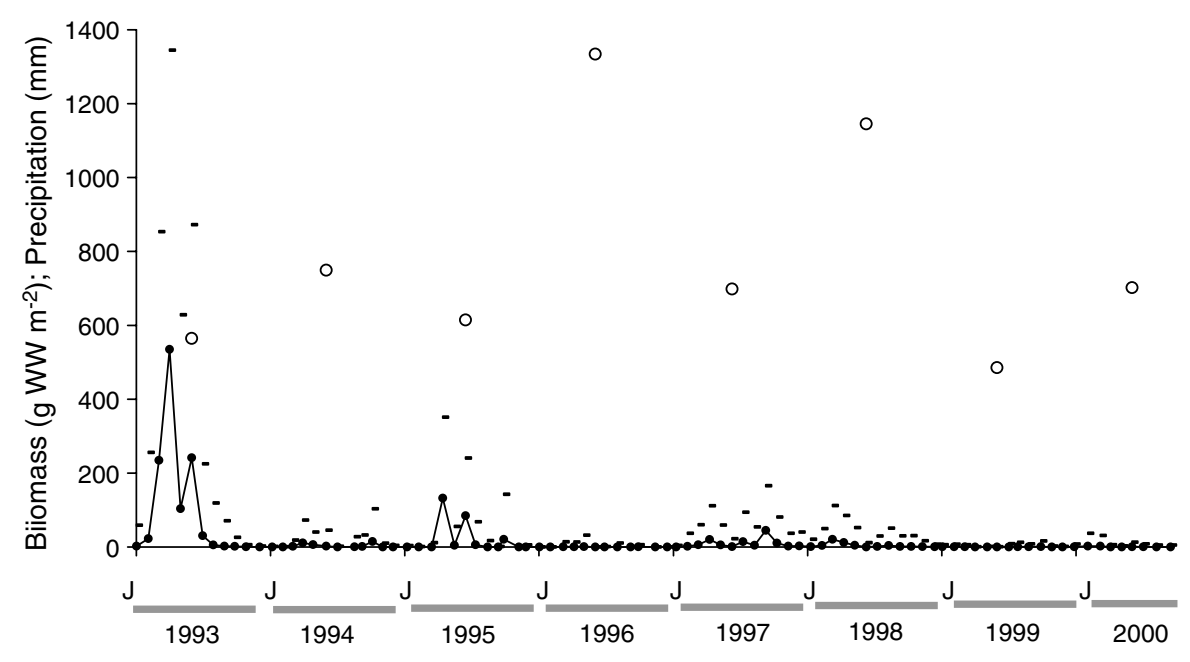

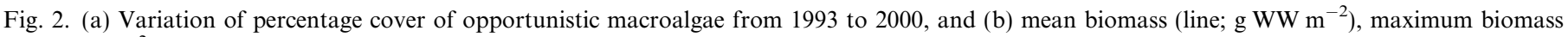
$\left(-; \mathrm{g} \mathrm{WW} \mathrm{m}^{-2}\right)$ and accumulated precipitation $(\mathrm{mm})$ from September to June (open circles) in the study area, from 1993 to 2000.

less important algal biomass peak could be observed in September followed by a decrease until winter (Marques et al., 1997) (Fig. 2). Concomitantly, the area occupied by Zostera noltii beds, which represented the richest habitat with regard to productivity and biodiversity, suffered a severe reduction especially from 1991 to 1997 (the area occupied decreased from approximately 15 ha in 1986 to $200 \mathrm{~m}^{2}$ in 1997). Such shift in the benthic primary producers affected the structure and functioning of the biological communities, including the species composition. Through time such modifications induced the emergence of a new selected trophic structure, which has been profusely analysed in abundant literature (e.g. Marques et al., 2003; Cardoso et al., 2004; Patrício and Marques, 2006).

Nevertheless, at least until a certain extent, this trend apparently reversed from 1998 after the implementation in late 1997, of experimental mitigation measures consisting of a decrease in the freshwater discharge proceeding from the Pranto River sluice as a consequence of a limited re-establishment of the communication between the two arms. In fact, we could observe a slow recovery of the area occupied by the macrophytes community and the cessation of green macroalgae (Ulva spp.) blooms (Martins et al., 1999, 2001, in press; Marques et al., 2003; Cardoso et al., 2004; Verdelhos et al., 2005; Lillebø et al., 2007; Neto et al., in press).

Therefore, for all the above reasons, this estuary is an ideal site for testing a tool, which aims to assess its response to anthropogenic influences (namely nutrient enrichment).

\subsubsection{Sampling procedure}

The intertidal zone of the south arm of the Mondego estuary, composed of soft sediments (mud, muddy sand and sand), was chosen as study site. Included in a wider monitoring survey, the sampling campaigns took place monthly, from January 1993 to September 2000. 
Total intertidal area. Based on aerial photographs of the entire south arm area and using GIS technology, the intertidal areas suitable for opportunistic macroalgae growth were estimated on 175 ha.

Macroalgae cover. The area of macroalgae-covered sediments in most of the intertidal areas of the south arm was plotted on maps drawn from aerial photographs. In order to increase plotting accuracy, the maps included all the identifiable landmarks in the surroundings, such as channels, patches of plants, posts and nearby buildings. Area of macroalgal cover was then estimated from the maps using a grid in which each square corresponded to $100 \mathrm{~m}^{2}$. Additionally, to each defined area was attributed one of three percentage of cover categories: (1) $0 \%$ (no algae); (2) $50 \%$ (patchy distribution of algae covering around $50 \%$ of the area) or (3) $100 \%$ (algae covering the entire area without bare sediment). Estimations were confirmed with field observations. Macroalgae cover of the entire system was then calculated according to Wither (2003) (for more details see Section 2.1.2.3).

Biomass. During low tide, a core was used to collect the opportunistic macroagae occurring in the soft sediments of the intertidal areas, over a sampling area of $141 \mathrm{~cm}^{2}$, and introduced into the sediment to a depth of $20 \mathrm{~cm}$ (five replicates). This yielded replicates with a volume of about $3 \mathrm{~L}$. In order to classify the whole water body, biomass figures (in $\mathrm{g} \mathrm{WW} \mathrm{m}^{-2}$ ) are expressed as mean values for the entire available intertidal area.

\section{Results}

\subsection{Sampling period}

In order to establish the time period better suited to capture the temporal dynamic of the biological quality element under assessment, the classification results obtained in three different sampling periods were compared. For every year, the three considered periods were: (1) from April to

Table 4

Classification results obtained for Option 1 and Option 2 when three different sampling periods are considered: (1) from April to June; (2) from March to July and (3) from April to September, from 1993 to 1996

\begin{tabular}{llll}
\hline Year & Time Period & EQS (Option 1) & EQS (Option 2) \\
\hline 1993 & April-June & M & P \\
& March-July & M & P \\
& April-September & G/M & M \\
& April-June & G & G \\
& March-July & G & G \\
& April-September & G & G \\
& April-June & G/M & P \\
& March-July & G/M & M \\
& April-September & G/M & M \\
& April-June & H & H \\
& March-July & H & H \\
& April-September & H & H \\
\hline
\end{tabular}

$\overline{\text { Ecological quality status (EQS): H. High; G. Good; M. Moderate and }}$ P. Poor.
June; (2) from March to July and (3) from April to September. The classification obtained for each Option, for the three periods, from 1993 to 1996, is shown in Table 4. Some points emerge from examination of the results:

1. The period from April to June presented always the same classification or worse EQS than other time periods considering both options.

2. The period from April to September (where the late summer peak of macroalgae usually occurs) provided, in general, better scores than the other time periods, showing a time dilution effect.

3. Sampling from April to June is in accordance with the precautionary principle. During this period the worse conditions are always captured and the monitoring effort is more cost-effective.

\subsection{Ecological quality status (EQS)}

The threshold values proposed by Scanlan et al. (2007) were tested against a range of data from the south arm of the Mondego estuary in years of different levels of impact, namely different levels of eutrophication symptoms. From Section 3.1, the EQS was calculated using monthly data collected from April to June, accounting for the period 1993-2000. Table 5 summarises the results obtained based on Option 1 and Option 2 and a list of the main results is synthesised below:

1. Both options captured the inter-annual variations regarding macroalgae dynamics in the study area, presenting worse classifications in 1993 and 1995, in accordance with the system evolution (see Fig. 2). After the implementation of preliminary mitigation measures to decrease the eutrophication symptoms felt in the system, the area exhibited a positive evolution with the decline of macroalgae blooms and the recovery of $Z$. noltii meadows. Both methodological options are correctly capturing this development.

2. In 1994, a classification of Good was given by both options. At first this result might look contradicting with the results of 1993 and 1995. However, it is well identified in this system that macroalgal blooms may not occur in rainy years, due to long intervals of low salinity, in coupled to strong currents occasioned by discharge from the tributary Pranto River (Martins et al., 1999, 2001 , in press). In reality, the accumulated precipitation (from September to June) in 1994 was higher than in 1993 and 1995 (see Fig. 2), explaining the inexistence of blooms. Although 1999 presented low accumulated precipitation, this meteorological event occurred after the implementation of mitigation measures that, between other effects, increased the system hydrodynamics, restricting macroalgal blooms development.

3. Both methodological options agreed on the classification regarding Good and High EQS. Nevertheless, sometimes, Option 1 upgraded one class status below 
Table 5

EQS for the south arm of the Mondego estuary, April-June from 1993 to 2000, based on Option 1: \% cover, biomass production of opportunistic macroalgae and areal coverage and Option 2: \% cover and areal coverage of opportunistic macroalgae

\begin{tabular}{|c|c|c|c|c|c|c|c|}
\hline \multirow[t]{2}{*}{ Year } & \multicolumn{4}{|l|}{ Option 1} & \multicolumn{3}{|l|}{ Option 2} \\
\hline & $\%$ Cover & Biomass (WW $\mathrm{g} \mathrm{m}^{-2}$ ) & Areal coverage (ha) & EQS & $\%$ Cover & Areal coverage (ha) & EQS \\
\hline 1993 & 32.42 & 294 & 57 & M & 32.42 & 57 & $\mathrm{P}$ \\
\hline 1994 & 13.34 & 7 & 23 & G & 13.34 & 23 & G \\
\hline 1995 & 27.39 & 74 & 48 & $\mathrm{G} / \mathrm{M}$ & 27.39 & 48 & $P$ \\
\hline 1996 & 4.32 & 1 & 8 & $\mathrm{H}$ & 4.32 & 8 & $\mathrm{H}$ \\
\hline 1997 & 10.01 & 9 & 18 & G & 10.01 & 18 & G \\
\hline 1998 & 6.93 & 6 & 12 & $\mathrm{G}$ & 6.93 & 12 & $\mathrm{G}$ \\
\hline 1999 & 2.52 & 0 & 4 & $\mathrm{H}$ & 2.52 & 4 & $\mathrm{H}$ \\
\hline 2000 & 3.09 & 0 & 5 & $\mathrm{H}$ & 3.09 & 5 & $\mathrm{H}$ \\
\hline
\end{tabular}

Ecological quality status (EQS): H. High; G. Good; M. Moderate and P. Poor.

Total available intertidal area for opportunistic macroalgae growth in the south arm $=175$ ha.

Good compared with Option 2. In these cases, Option 2 results appear to be more in accordance with the real state of the system.

4. 1997 exhibited a Good EQS despite corresponding, based on our knowledge about the system, to a worse condition than 1996 or 1998-2000. None of the methodological options was able to capture this trend regarding the system evolution.

\section{Discussion}

\subsection{Sampling period}

It is well known that the spatial and temporal variability, inherent to natural systems, implies fundamental problems for monitoring and consequent ecological quality assessment. Single annual samples intending to meet some policy objective, for example, may have little value in assessing quality, especially for impacted water bodies where biotic structure and abundance, and chemical drivers such as nutrient concentrations, can vary through orders of magnitude within an annual cycle (Irvine, 2004). Furthermore, regarding opportunistic macroalgae, the timing of maxima can be difficult to predict, depending on several factors (e.g. latitude, hydrodynamics, etc.), and assumptions of seasonal pattern in one water body based on experience from quite different ones should be avoided.

Nevertheless, for management purposes, a clear definition of the sampling period becomes indispensable if the aim is to accurately capture the system's ecological status. In our case study - the Mondego estuary, a small mesotidal well-mixed estuary - results suggest that sampling should be conducted monthly between April and June in order to capture the typical spring macroalgae peak. This time period, considering both options, presented always the same or worse EQS classification compared to the other periods of the year.

While a comprehensive definition of the precautionary principle was never formally adopted by the European Union, a working definition and implementation strategy for the EU context has been proposed by Fisher et al. (2006): “ . . where, following an assessment of available scientific information, there are reasonable grounds for concern for the possibility of adverse effects but scientific uncertainty persists, provisional risk management measures based on a broad cost/benefit analysis whereby priority will be given to human health and the environment, necessary to ensure the chosen high level of protection in the Community and proportionate to this level of protection, may be adopted, pending further scientific information for a more comprehensive risk assessment, without having to wait until the reality and seriousness of those adverse effects become fully apparent". In our opinion, sampling from April to June, in our latitude, is in accordance with the abovementioned precautionary principle, capturing the worse annual ecological condition regarding this biological quality element. Besides, the classifications obtained during this time period seem to illustrate correctly the expert judgment about the system ecological status from 1993 to 2000 (Marques et al., 2003; Verdelhos et al., 2005).

\subsection{Assessment method: Option 1 vs Option 2}

It is worldwide accepted that the methods available to assess the condition of marine benthic plant communities are not comparable to the large panoply of indices existing for some other groups of organisms. Moreover, in Portugal, there are in general no accessible monitoring data series, and published sampling sets are usually small and rare. Therefore, having in mind the implementation of the WFD in Portugal and regarding opportunistic macroalgae as ecological quality element, the aim of this paper has been primarily to test the approach proposed by Scanlan et al. (2007) (Option 1). In addition, a second tool (Option 2) was tested in order to compare the accuracy of the two methodologies to derive an EQS.

Results suggest that both options captured the essence of inter-annual variations of macroalgae dynamics in the south arm of the Mondego estuary, providing worse classifications in 1993 followed by 1995. According to our 
knowledge on the system, these results reflect the combined effect of increased water residence time and high nutrients concentration, which have caused the emergence of clear eutrophication symptoms since early 90s (Marques et al., 2003). In 1998, after the implementation of some preliminary mitigation measures - (1) decrease in the freshwater discharge proceeding from the Pranto River sluice and (2) the limited re-establishment of the communication between the 2 estuarine arms (1997), which improved water circulation in the south arm of the estuary - the area began to give signs of recovery with the cessation of extensive green macroalgae blooms (among others) (see Fig. 2). Again, both assessment methods correctly captured this positive evolution of the system.

Moreover, in all situations, Option 1 and Option 2 agreed on the classification regarding Good and High EQS, suggesting that, at least in this estuary, the threshold values proposed by Scanlan et al. (2007) seem to be adequate for these two classes.

Nevertheless, sometimes, Option 1 upgraded one class status below Good when compared with Option 2. In such cases, Option 2 results were more in accordance with our perception of the real state of the system. Therefore if the hybrid classification given by Option 1 (e.g. Good/Moderate or Moderate/Poor) were avoided, the match between classifications out coming from both methodologies would increase. In other words, if the Good/Moderate classification given by Option 1 changed to Moderate and the Moderate/Poor classification changed to Poor, by adjusting slightly the threshold values, both options would give similar results. From the system evolution and from the WFD definitions (EEC, 2000), we suggest the use of Option 2 scale, either because it is more realistic and in better accordance with the system environmental condition along the study period, and also because it avoids imprecise classifications results. In fact, Scanlan et al. (2007) claim that threshold values for Moderate/Poor and Poor/Bad are still under discussion, further scrutiny of existing data, as well as the acquisition of new data, being required before these can be determined with appropriate confidence. Following the results of the Mondego estuary case study, it would be interesting to spend some time and energy adjusting these values.

Although secondary, the issue of biomass values expressed as wet rather than dry weight per square metre might also be discussed. Scanlan et al. (2007) defend that wet weight is a commonly used measure, and for practical reasons it is a much easier and less time-consuming determinant than dry weight. Although these arguments are correct, it is also well known that dry weight values have a clearer determination procedure and are, therefore, more precise and easy to compare. Is the laboratorial process to estimate dry weight that difficult and so time-consuming to justify the choice of using wet weight?

Another interesting question is related with the initial difficulties concerning the relative size of water bodies pointed out by Scanlan et al. (2007). Early consideration of inter-calibration data (Wells, personal communication) has highlighted that not taking overall water body size into account would lead to over-estimation of quality status. To account for this, Scanlan et al. (2007) proposed that areal coverage (in hectares) should lower the class of a water body, as derived from Table 2, by one or more classes depending on the total area of algal mats. Fig. 3 illustrates a numerical example where the effect that system size can have in the final classification score is clearly demonstrated. For instance, two systems with the same areal coverage of opportunistic macroalgae but one (situation B) being 10

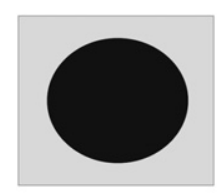

Situation A

Total intertidal area: 100 ha Areal coverage: 70 ha Percentage cover: $70 \%$ EcoQ: Poor
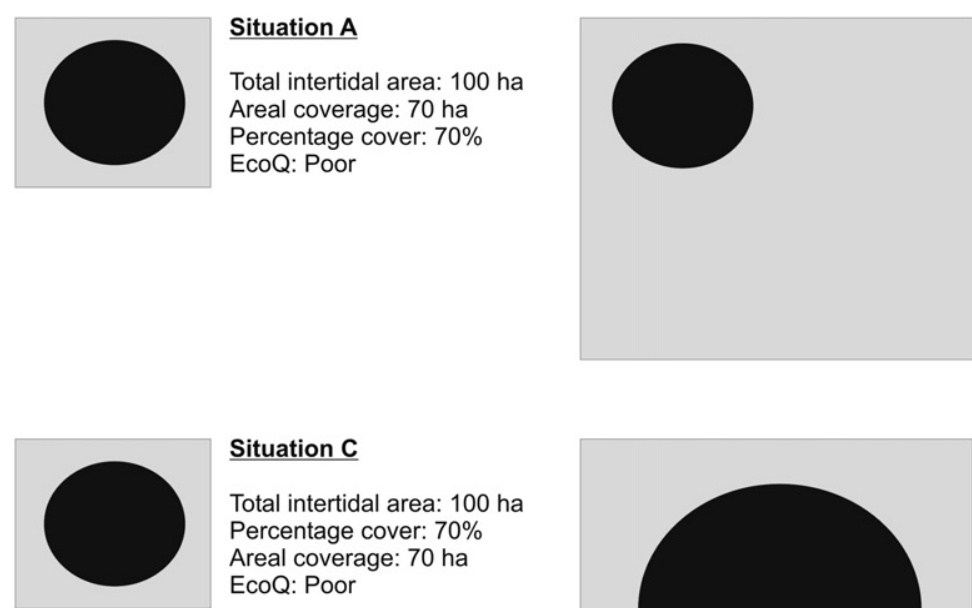

Situation C

Total intertidal area: 100 ha Percentage cover: $70 \%$ Areal coverage: 70 ha EcoQ: Poor

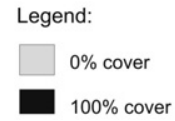

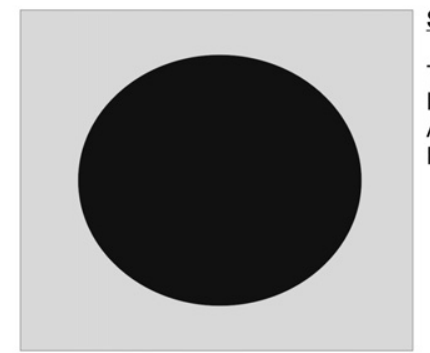

\section{Situation D}

Total intertidal area: 1000 ha Percentage cover: $70 \%$ Areal coverage: 700 ha EcoQ: Bad

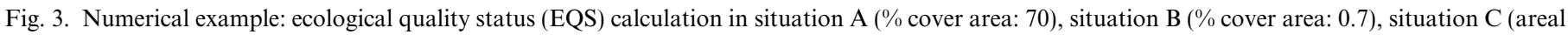
coverage: $70 \mathrm{ha}$ ) and situation D (areal coverage: $700 \mathrm{ha}$ ). 
times bigger than the other (situation A) may present distinct EQS, with a worse quality status attributed to the smaller system. On the other hand, two systems with the same percentage cover but one (situation D) being ten times bigger than the other (situation C) can, again, show different quality status. In this case, according to the opportunistic macroalgae assessment method applied (for the sake of this exercise, Option 2 was used), the larger system presents worse EQS. Consequently, both methodological options are sensitive to this scale issue.

In conclusion, if Option 2 works well and is less expensive, why do not adopt it? Many studies have identified levels of biomass at which, or above, significant harmful effects on biota have been, or may be, observed (e.g. Valiela et al., 1997; Österling and Pihl, 2001; Cummins et al., 2004). Therefore, biomass values, whenever available, should reinforce the classification method and be used to turn results more accurate. However, if biomass data are not available, then Option 1 is not applicable. In this situation, from aerial photos and scientific literature it might be achievable to get the right information concerning percentage cover. Information regarding "total available intertidal area for opportunistic macroalgae growth", "areal coverage" and "percentage cover" are afterwards possible to calculate, and consequently to produce a system's ecological status evaluation with accurate results.

Another pertinent question that could be raised concerns the fact that to monitor macroalgae dynamics to infer about EQS of a system is - at least during some periods - unrealistic. This question is even more relevant when it is known that in 1996 the Z. noltii beds were suffering a dramatic decrease from 15 ha to $200 \mathrm{~m}^{2}$ from 1986 until 1997, and the classification results for the macroalgae biological element for the year 1996 were High in both option 1 and 2. In fact, in 1994-1997/98, there were no macroalgal blooms but also there was a decline in $Z$. noltii meadows. Would not it be more realistic to develop a methodology based on macroalgae and rooted-macrophytes simultaneously? Probably yes. However, there are some facts that is important to take into consideration:

(1) Macroalgae is only one of the biological elements to take into consideration in attributing the final EQS of a system. In order to get the final system classification the EQS derive from fish, benthic macroinvertebrates, phytoplankton, macrophytes and (opportunistic) macroalgae should be all accounted for.

(2) In our opinion, one of the potential strengths of taking into consideration several biological elements is to account for the distinct response times that each ecosystem component has subsequent to a disturbance event (namely, nutrient enrichment). It is well known that phytoplankton may show a faster reaction than benthic macroinvertebrates and similarly opportunistic macroalgae react faster than rooted-macrophytes. For example, in our case study, during the 90 s there was an increase in turbidity and in the nutrient concentrations available for the primary producers and an increase in the residence time in the south arm (due to the reduced flow upstream). These were the factors favouring the appearance of opportunistic green macroalgal blooms. Only after that, Z. noltii (adapting more slowly to the environmental changes) started to decline. Therefore, evaluating separately these two biological elements, macroalgae may be used as "early warning" signs regarding nutrient' pressure.

Nevertheless, due to the complex nature of this topic, these aspects need further discussion and should be considered in future works.

Finally, regarding Portuguese transitional waters, the results of this study have to be compared with similar studies in other systems belonging to the same type and other comparable water types, in order to turn the proposed methodology reliable to assess the ecological quality status based on opportunistic macroalgae as a biological quality element.

\section{Acknowledgments}

The present study was carried out in the scope of the research projects RECITAL - Reference conditions and inter-calibration in Portuguese transitional and coastal waters (contract no. 2005/056/INAG) and EFICAS Effects of natural stress generated by freshwater discharges in the benthic invertebrate estuarine communities and its influence on the assessment of the benthic ecological status (POCI/MAR/61324/2004). It was also supported by FCT (Portuguese National Board of Scientific Research) through three grants (SFRH/BPD/26604/2005, SFRH/ BPD/20707/2004, SFRH/BD/24430/2005). This work had the institutional support of INAG-National Water Institute (Portugal). Thank you to all colleagues that have contributed for this study, namely through valuable field and laboratory work.

\section{References}

Bettencourt, A., Bricker, S.B., Ferreira, J.G., Franco, A., Marques, J.C., Melo, J.J., Nobre, A., Ramos, L., Reis, C.S., Salas, F., Silva, M.C., Simas, T., Wolff, W., 2004. Typology and reference conditions for Portuguese transitional and coastal waters. Development of guidelines for the application of the European Union Water Framework Directive. Edição IMAR/INAG, pp. 98.

Bricker, S.B., Clement, C.G., Pirhalla, D.E., Orlando, S.P., Farrow, D.R.G., 1999. National estuarine eutrophication assessment: effects of nutrient enrichment in the nation's estuaries. NOAA, National Ocean Service, Special Projects Office and the National Centers for Coastal Ocean Science, Silver Spring, MD, pp. 71.

Cardoso, P.G., Pardal, M.A., Raffaelli, D., Baeta, A., Marques, J.C., 2004. Macroinvertebrate response to different species of macroalgal mats and the role of disturbance history. Journal of Experimental Marine Biology and Ecology 308, 207-220. 
Cardoso, P.G., Bankovic, M., Raffaelli, D., Pardal, M.A., 2007. Polychaete assemblages as indicators of habitat recovery in a temperate estuary under eutrophication. Estuarine, Coastal and Shelf Science 71, 301-308.

Constanza, R., d'Arge, R., de Groot, R., Fraber, S., Grasso, M., Hannon, B., Limburg, K., Naeem, S., O’Neill, R.V., Paruelo, J., Raskin, R.G., Sutton, P., van den Belt, M., 1997. The value of the world's ecosystem services and natural capital. Nature 387, 253-260.

Crooks, S., Turner, R.K., 1999. Integrated coastal management: sustaining estuarine natural resources. In: Nedwell, D.B., Raffaelli, D.G. (Eds.), Estuaries: Advances in Ecological Research, vol. 29. Academic Press, New York, pp. 241-289.

Crowe, T.P., Thomson, R.C., Bray, S., Hawking, S.J., 2000. Impacts of anthropogenic stress on rock intertidal communities. Journal of Aquatic Ecosystem Stress and Recovery 7, 273-297.

Cummins, S.P., Roberts, D.E., Zimmerman, K.D., 2004. Effects of the green macroalga Enteromorpha intestinalis on macrobenthic and seagrass assemblages in a shallow coastal estuary. Marine Ecology Progress Series 266, 77-87.

Dauer, D.M., 1993. Biological criteria, environmental health and estuarine macrobenthic community structure. Marine Pollution Bulletin 26 (5), 249-257.

EC, 2003. Towards a guidance on establishment of the intercalibration network and the process on the intercalibration exercise. Produced by: CIS Working Group 2.5. (Intercalibration), Common Implementation Strategy of the Water Framework Directive, European Commission, p. 54 .

EEC, 2000. Directive 2000/60/EC of the European Parliament and of the Council of 23 October 2000 establishing a framework for Community action in the field of water policy. Official Journal of the European Communities 43, 1-72.

Fisher, E., Jones, J., Schomberg, R. (Eds.), 2006. Implementing the Precautionary Principle: Perspectives and Prospects. Edward Elgar, Cheltenham, UK and Northampton, MA, US.

Flindt, M.R., Kamp-Nielsen, L., Marques, J.C., Pardal, M.A., Bocci, M., Bendoricchio, G., Salomonsen, J., Nielsen, S.N., Jørgensen, S.E., 1997. Description of the three shallow estuaries: Mondego River (Portugal), Roskilde Fjord (Denmark), and the Lagoon of Venice (Italy). Ecological Modelling 102, 17-31.

Gibson, G.R., Bowman, M.L., Gerritsen, J., Snyder, B.D., 2000. Estuarine and Coastal Marine Waters: Bioassessment and Biocriteria Technical Guidance. EPA 822-B-00-024. U.S. Environmental Protection Agency, Office of Water, Washington, DC.

Irvine, K., 2004. Classifying ecological status under the European Water Framework Directive: the need for monitoring to account for natural variability. Aquatic Conservation: Marine Freshwater Ecosystems 14, $107-112$.

Lillebø, A.I., Neto, J.M., Martins, I., Verdelhos, T., Leston, S., Cardoso, P.G., Ferreira, S., Marques, J.C., Pardal, M.A., 2005. Management of a shallow temperate estuary to control eutrophication: The effect of hydrodynamics on the system's nutrient loading. Estuarine, Coastal and Shelf Science 65, 697-707.

Lillebø, A.I., Teixeira, H., Pardal, M.A., Marques, J.C., 2007. Applying quality status criteria to a temperate estuary before and after the mitigation measures to reduce eutrophication symptoms. Estuarine, Coastal and Shelf Science 72, 177-187.

Marques, J.C., Maranhão, P., Pardal, M.A., 1993. Human impact assessment on the subtidal macrobenthic community structure in the Mondego estuary (Western Portugal). Estuarine Coastal and Shelf Science 37, 403-419.

Marques, J.C., Nielsen, S.N., Pardal, M.A., Jørgensen, S.E., 1997. Impact of eutrophication and river management within a framework of ecosystem theories. Ecological Modelling 166, 147-168.

Marques, J.C., Nielsen, S.N., Pardal, M.A., Jørgensen, S.E., 2003. Impact of eutrophication and river management within a framework of ecosystem theories. Ecological Modelling 166, 147-168.
Martins, I., Oliveira, J.M., Flindt, M.R., Marques, J.C., 1999. The effect of salinity on the growth rate of the macroalgae Enteromorpha intestinalis (Chlorophyta) in the Mondego estuary (west Portugal). Acta Oecologica 20, 259-265.

Martins, I., Pardal, M.A., Lillebø, A.I., Flindt, M.R., Marques, J.C., 2001. Hydrodynamics as a major factor controlling the occurrence of green macroalgae blooms in an eutrophic estuary: a case study. Estuarine Coastal and Shelf Science 52, 165-177.

Martins, I., Lopes, R.J., Lillebø, A.I., Neto, J.M., Pardal, M.A., Ferreira, J.G., Marques, J.C., in press. Significant variations in the productivity of green macroalgae in a mesotidal estuary: implications to the nutrient loading of the system and the adjacent coastal area. Marine Pollution Bulletin. doi:10.1016/j.marpolbul.2007.01.023.

Neto, J.M., Flindt, M.R., Marques, J.C., Pardal, M.A., in press. Modelling nutrient mass balance in a temperate macro-tidal estuary: implications to management. Estuarine, Coastal and Shelf Science. doi:10.1016/j.ecss.2007.06.013.

Nixon, S.W., 1995. Coastal marine eutrophication: a definition, social causes, and future concerns. Ophelia 41, 199-219.

Odum, E.P., 1985. Trends expected in stressed ecosystems. BioScience 35, $419-422$.

Österling, M., Pihl, L., 2001. Effects of filamentous green algal mats on benthic macrofaunal functional feeding groups. Journal of Experimental Marine Biology and Ecology 263, 159-183.

Paerl, H.W., 1999. Cultural eutrophication of shallow coastal waters: coupling changing anthropogenic nutrient inputs to regional management approaches. Limnologica 29, 249-254.

Panayotidis, P., Montesanto, B., Orfanidis, S., 2004. Use of low-budget monitoring of macroalgae to implement the European Water Framework Directive. Journal of Applied Phycology 16, 49-59.

Patrício, J., Marques, J.C., 2006. Mass balanced models of the food web in three areas along a gradient of eutrophication symptoms in the south arm of the Mondego estuary (Portugal). Ecological Modelling 197, 21 34.

Raffaelli, D.G., Balls, P., Way, S., Patterson, I.J., Hohmann, S., Corp, N., 1999. Major long-term changes in the ecology of the Ythan estuary, Scotland: how important are physical factors? Aquatic Conservation: Marine Freshwater Ecosystems 9, 219-236.

Scanlan, C.M., Foden, J., Wells, E., Best, M.A., 2007. The monitoring of opportunistic macroalgal blooms for the water framework directive. Marine Pollution Bulletin 55, 162-171.

Schramm, W., Nienhuis, P.H., 1996. In: Marine Benthic Vegetation: Ecological Studies, vol. 123. Springer-Verlag, Berlin.

Sfriso, A., Pavoni, B., Marcomini, A., Orio, A.A., 1992. Macroalgae, nutrient cycles and pollutants in the lagoon of Venice. Estuaries 15, $517-528$.

Thiel, M., Watling, L., 1998. Effects of green algal mats on infaunal colonization of a New England mud flat - long-lasting but highly localized effects. Hydrobiologia 375/376, 17789.

Valiela, I., Foreman, K., LaMontagne, M., Hersh, D., Costa, J., Peckol, P., DeMeo-Anderson, B., D'Avanzo, C., Babione, M., Sham, C.-H., Brawley, J., Lajtha, K., 1992. Couplings of watersheds and coastal waters: sources and consequences of nutrient enrichment in Waquoit Bay, Massachusetts. Estuaries 15, 443-457.

Valiela, I., McClelland, J., Hauxwell, J., Behr, P.J., Hersh, D., Foreman, K., 1997. Macroalgal blooms in shallow estuaries: controls and ecophysiological and ecosystem consequences. Limnology and Oceanography 42 (5), 1105-1118.

Verdelhos, T., Neto, J.M., Marques, J.C., Pardal, M.A., 2005. The effect of eutrophication abatement on the bivalve Scrobicularia plana. Estuarine, Coastal and Shelf Science 63, 261-268.

Wither, A., 2003. Guidance for sites potentially impacted by algal mats (green seaweed). EC Habitats Directive Technical Advisory Group report WQTAG07c. 